\title{
REVIEW
}

\section{Central non-glucocorticoid inhibitors of the hypothalamo-pituitary-adrenal axis}

\author{
D S Jessop \\ Division of Medicine, Department of Clinical Medicine, University of Bristol, Marlborough Street, Bristol BS2 8HW, UK
}

\section{Introduction}

The popular perception of stress is that of social or work tensions and pressures that have an overall negative influence often accompanied by increased frequency of illness. However, stress is not all bad. A healthy response to acute stress is crucial for our interaction with the environment and for our ability to deal with everyday challenges, either physical or psychological. The key is to be able to terminate a response to stress when the stressor is no longer present. Failure to terminate a response to acute stress can result in the syndrome of chronic stress which is associated with inappropriately elevated secretion of glucocorticoids, with consequent immunosuppression and predisposition to infection and illness.

Responses of the hypothalamo-pituitary-adrenal (HPA) axis to stress are mediated principally through the neuropeptides corticotrophin-releasing hormone (CRH) and arginine vasopressin (AVP) which are synthesised in the parvocellular subdivision of the hypothalamic paraventricular nucleus (PVN) (for review see Buckingham et al. 1997). CRH and AVP are transported down axonal projections to the median eminence (ME) where they are secreted into the hypophysial portal blood system to synergistically stimulate the release of adrenorticotrophin (ACTH) from corticotroph cells in the anterior pituitary, leading to increased secretion of glucocorticoids from the adrenal cortex (Fig. 1). Glucocorticoid feedback at the hippocampal and hypothalamic levels is a well-recognised mechanism for inhibiting basal and stress-induced HPA axis activity (for a review see De Kloet et al. 1998), but there is also considerable evidence for the existence of non-glucocortocoid mechanisms of inhibition. In adrenalectomised animal models, basal plasma ACTH concentrations are elevated but not maximally, since stressors such as ether (Rees et al. 1971), restraint (Chowdrey et al. 1991) and haemorrhage (Darlington et al. 1990) are capable of further stimulating ACTH release. In addition, a chronic osmotic stimulus inhibits ACTH release through a mechanism which, because it occurs in adrenalectomised rats, cannot be regulated by glucocorticoids
(Jessop et al. 1990). Thus the HPA axis is subject to mechanisms of tonic inhibition which operate independently of glucocorticoids.

Inhibitory agents may act at any or all levels of the HPA axis. Lesioning of selective hypothalamic nuclei can enhance the HPA axis response to some stressors (Herman \& Cullinan 1997), providing evidence for endogenous hypothalamic inhibitors acting on $\mathrm{CRH}$ and/or AVP expression within the PVN. Observations of pulsatile ACTH secretion after complete lesioning of the PVN (and elimination of $\mathrm{CRH}$ from the $\mathrm{ME}$ ) have revealed a surprising degree of residual pituitary-adrenocortical activity (Boyle et al. 1997). Total PVN lesioning was still accompanied by an ACTH response to some cytokines (Kovacs \& Elenkov 1995), and electrical lesions that destroyed the entire hypothalamus did not prevent a response to the stress of laparotomy (Witorsch \& Brodish 1972). One explanation for these results is that the lesions eliminate not only hypothalamic corticotrophin-releasing factors but also inhibitory factors which may be acting to block the secretion of ACTH from the anterior pituitary. Further evidence for the release of ACTH inhibitors into hypophysial portal blood was supplied by the report that hypothalamo-pituitary disconnection in sheep was accompanied by increased ACTH and cortisol secretion (Engler et al. 1988). Although some of these results could be explained by the existence of novel extrahypothalamic ACTH-releasing factors, cumulative evidence is compelling for the existence of compounds acting on the hypothalamus and/or anterior pituitary that can inhibit the stress response.

The purpose of this review is to distil the literature on non-glucocorticoid inhibitors of the HPA axis (briefly reviewed by Grossman \& Tsagarakis 1989 and Engler et al. 1994) and to assess the extent to which this information has contributed to our understanding of the biochemical mechanisms of stress control. The emphasis throughout will be on inhibitory agents that have the potential to operate at the hypothalamus or the anterior pituitary, rather than at the adrenal cortex. Compounds directly affecting glucocorticogenesis have been the 


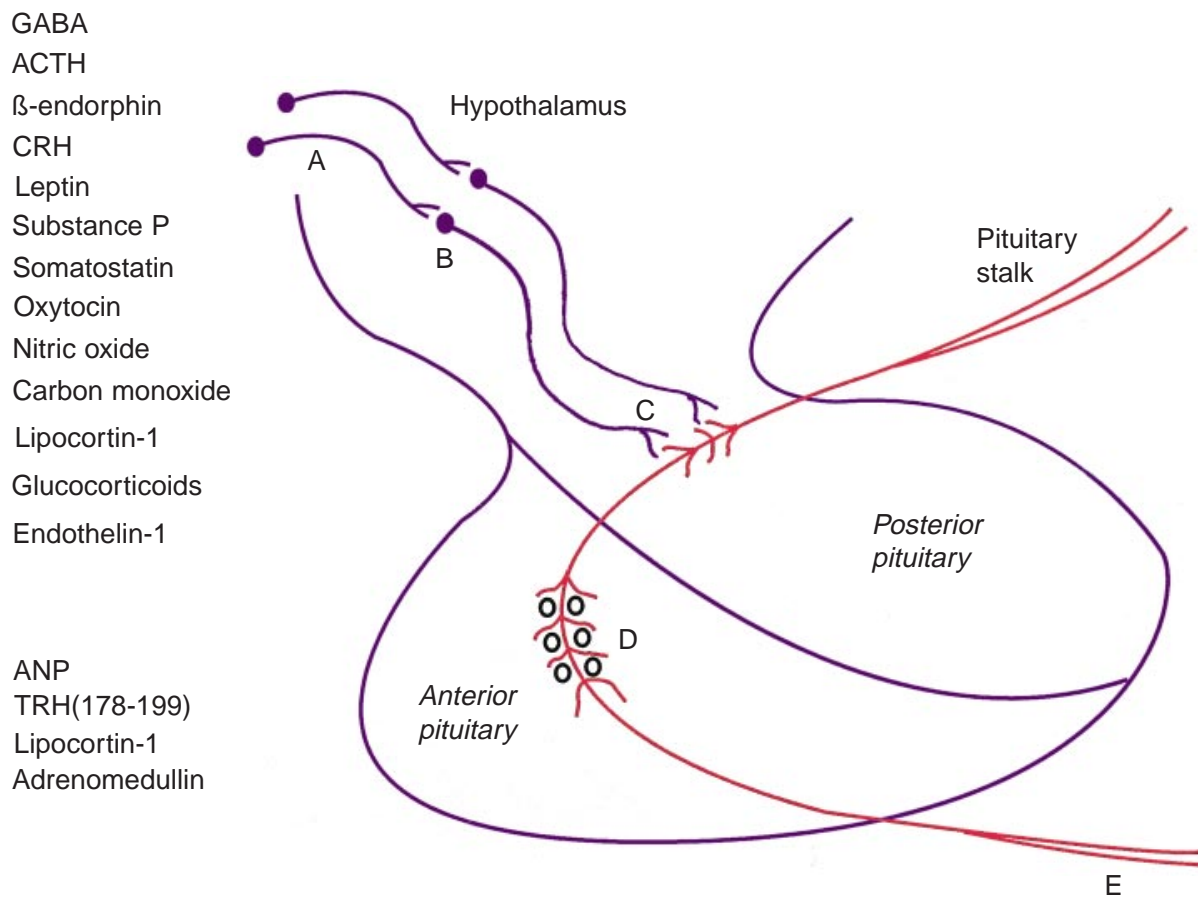

Figure 1 Schematic diagram of the hypothalamo-pituitary axis. CRH and AVP are secreted under neural control (A) from the parvocellular neurons of the hypothalamic PVN (B) at the level of the ME into the hypophysial portal blood system (C) and transported to the corticotrophs of the anterior pituitary (D) where they synergistically stimulate the release of ACTH into the general circulation (E). ACTH inhibitory agents are listed according to their major hypothalamic or anterior pituitary site(s) of action.

subject of a recent review (Ehrhart-Bornstein et al. 1998).

\section{$\gamma$-Aminobutyric acid (GABA)}

The neurotransmitter GABA is a well-established inhibitor of ACTH release (Makara \& Stark 1974), probably through a central action on hypothalamic CRH. GABA agonists are capable of inhibiting serotonin-induced CRH release from hypothalami in culture (Calogero et al. 1988a), and in vivo injection of the GABA A receptor antagonist bicuculline into the dorsomedial hypothalamus resulted in increased plasma ACTH and corticosterone (Keim \& Shekhar 1996). Thus the HPA axis appears to be under tonic GABA inhibition at the hypothalamic level, mediated through GABA A receptors, although GABA B receptors have also been implicated (Hausler et al. 1993). GABA is located within CRH-containing neurons in the PVN (Meister et al. 1988) and also has the potential to influence $\mathrm{CRH}$ expression through GABAergic neurons within the bed nucleus of the stria terminalis and preoptic nuclei which project into the PVN (reviewed by Herman \& Cullinan 1997). Evidence that neurosteroid analogues with GABA A receptor agonistic properties can attenuate
HPA axis responses to stress (Reddy \& Kulkarni 1996, Patchev et al. 1997) may suggest a cooperative stressprotective mechanism operating between GABA and selective neurosteroids. The GABA transaminase inhibitor sodium valproate has been employed clinically to reduce ACTH secretion in some patients with Nelson's syndrome, but this has not been observed in normal subjects (Torpy et al. 1995).

\section{$\beta$-Endorphin}

The HPA axis can probably regulate its own activity through feedback by neuropeptides. Proopiomelanocortin (POMC) mRNA is synthesised in the arcuate nucleus of the hypothalamus, and the POMC products ACTH and $\beta$-endorphin are transported through axonal projections to the parvocellular subdivision of the PVN (Sawchencko et al. 1982, Kiss et al. 1984) where they abut perikarya of CRH-containing neurons (Liposits et al. 1988). Human studies using the morphine antagonist naloxone have established that endogenous opioids can inhibit HPA axis activity (Grossman \& Besser 1982, Torpy et al. 1997). In one study in which normal human subjects received an infusion of $\beta$-endorphin, an abnormal response 
to insulin-induced hypoglycaemia was observed, although no overall inhibition of HPA axis activity occurred (Inder et al. 1996). This was probably due to poor penetration of the blood-brain barrier by $\beta$-endorphin, in contrast with naloxone which is lipophilic. In horses infused i.v. with a low dose of naloxone, basal plasma concentrations of ACTH and cortisol were elevated (Alexander \& Irvine 1995). Opioid inhibition of the HPA axis is most probably exerted at the hypothalamic level, and may be mediated through AVP rather than CRH (Delitala et al. 1994), although opioids are capable of inhibiting the release of CRH from rat hypothalami in vitro (Calogero et al. 1988b, Tsagarakis et al. 1989, Tsagarakis et al. 1990).

Although the inhibitory effect of endogenous opioids has been well documented in rats and humans, it is interesting to note that earlier work demonstrating a stimulatory naloxone-reversible effect of opioids on HPA axis activity in rats (Buckingham \& Cooper 1986) has recently gained renewed support from a paper showing that central injection of $\beta$-endorphin stimulated rat plasma $\mathrm{ACTH}$, an effect that could be prevented by naloxone or by injection of $\beta$-endorphin antiserum (Yamauchi et al. 1997). These apparently paradoxical reports of the effects of opioids within and between species may be reconciled by proposing that, if these actions reflect short loop feedback inhibition of $\mathrm{CRH}$ synthesis, then the effects may be concentration-dependent, such that increasing central concentrations of POMC peptide products may stimulate $\mathrm{CRH}$ expression to a maximum point beyond which POMC peptides become inhibitory. The observed ability of CRH to either stimulate (Ono et al. 1985) or inhibit (Calogero et al. 1988b) its own release suggests a mechanism whereby $\beta$-endorphin might exert opposing concentration-dependent effects upon the HPA axis, mediated by CRH.

\section{Atrial natriuretic peptide (ANP)}

In addition to the integral role of ANP in maintaining electrolyte and fluid homoeostasis through inhibition of aldosterone and AVP release, there is considerable evidence that ANP can also act as a corticotrophin-inhibitory factor. ANP was initially reported to inhibit the release of $\mathrm{CRH}-$ and AVP-stimulated ACTH from rat anterior pituitary cells (Antoni \& Dayanithi 1989). This phenomenon was highly sensitive to pulsatile pretreatment of the cells with CRH and AVP (Antoni \& Dayanithi 1990), conditions resembling those occurring in vivo in hypophysial portal blood. There is physiological potential for an action of ANP at the pituitary, since significant amounts of ANP are secreted from the hypothalamus into hypophysial portal blood (Lim et al. 1994) and ANP receptors are located within the anterior pituitary. However, these early promising results could not be reproduced in humans infused with ANP (Ur et al. 1991, Wittert et al. 1993).
The inability of physiological doses of peripheral ANP to attenuate HPA axis activity in man, together with evidence that ANP can inhibit the release of $\mathrm{CRH}$ from rat hypothalami in vitro (Ibanez-Santos et al. 1990), suggested that, if ANP did influence the HPA axis, the peptide was likely to be acting at the hypothalamic rather than at the pituitary level. This hypothesis proposing a central site of action was almost immediately controverted by the demonstration that central injection of ANP antiserum had no effect upon basal ACTH release (Fink et al. 1991, Franci et al. 1992) but when administered peripherally resulted in elevated plasma ACTH and corticosterone levels in rats (Fink et al. 1991). These observations switched attention back to an inhibitory role for ANP at the anterior pituitary and are supported by data showing a correlation between rat plasma ACTH and ANP during blood volume expansion (Jezova et al. 1994) and a potent inhibition by ANP of POMC expression in cultured mouse AtT-20 cells (Tan et al. 1994).

Despite numerous studies in support of a physiological inhibitory role for ANP over ACTH release, such a role remains controversial. Continuous perifusion of ANP in an equine pituitary cell system did not alter ACTH responses to pulsatile AVP (Mulligan et al. 1997) and ANP perfusion had no effect upon CRH- or AVP-stimulated ACTH release from cultured ovine or rat anterior pituitary cells (Bowman et al. 1997). ANP had no effect on basal or CRH-stimulated plasma ACTH in patients with Cushing's or Addison's disease (Ambrosi et al. 1994) and did not alter the ACTH response to a morning CRH test (Kellner et al. 1995). However, in the latter study, evening plasma ACTH levels were decreased during ANP infusion. The significance of this is that most human studies are performed in the morning during a period when the pituitary may be refractory to any effects of ANP. An evening response to ANP may reflect increased HPA axis sensitivity through facilitation (Dallman et al. 1992). Further human studies performed in the evening with ANP during this period of the circadian rhythm might be revealing in this respect, since the work of Antoni \& Dayanathi (1990) clearly shows the importance of the relationship between pituitary conditioning and sensitivity to ANP.

In contrast with ANP, C-type natriuretic peptide (CNP) has been shown to stimulate the release of ACTH in sheep (Charles et al. 1995) and cortisol in man (Kellner et al. 1997). mRNA for CNP receptors has been located within the anterior pituitary (Grandclement et al. 1995), and ANP at high concentrations can bind to CNP receptors. Therefore the failure of some groups to show an inhibitory effect of ANP may be due to non-specific binding of ANP to CNP receptors in the pituitary following administration of supraphysiological doses of ANP. ANP acting through CNP receptors may result in activation of the HPA axis, which could mask any inhibitory effects mediated specifically through ANP 
receptors. This mechanism would be difficult to explain if both ANP and CNP receptors were mainly expressed in pituitary corticotrophs, since both are linked to the common intracellular pathway of guanylate cyclase. However, CNP receptor mRNA is distributed throughout other anterior pituitary cell types such as lactotrophs and gonadotrophs (Grandclement et al. 1995) which may influence corticotroph activity through intercellular crosstalk. This stimulatory effect of ANP acting through CNP receptors may explain the report of enhanced effects on ACTH and cortisol release by an infusion of high-dose ANP, after an initial period of inhibition (Bierwolf et al. 1998).

\section{Leptin}

The protein leptin, which is produced in adipocytes, is a potent inhibitor of food intake and an important regulator of body weight. Because CRH also has anorectic properties, it has been proposed that the actions of leptin might be mediated via hypothalamic CRH. Subcutaneous infusion of leptin decreased CRH mRNA levels in the PVN of obese mice (Huang et al. 1998) and leptin blocked $\mathrm{CRH}$ release from perfused rat hypothalami in vitro while having no effect on ACTH release from cultured anterior pituitary cells (Heiman et al. 1997). Leptin has also been reported to inhibit ACTH and corticosterone increases induced by a restraint stress in vivo in mice (Heiman et al. 1997). Leptin receptor mRNA is present in the anterior pituitary as well as in the hypothalamus (Raber et al. 1997), conferring on leptin the potential to act at both the hypothalamus and pituitary.

In contrast with these observations, centrally injected microgram amounts of leptin increased CRH mRNA in the PVN (Schwartz et al. 1996) and increased circulating corticosterone (van Dijk et al. 1997). Leptin also stimulated the release of CRH from hypothalamic explants in vitro (Costa et al. 1997, Raber et al. 1997). These discrepancies between different laboratories are not easy to explain. Most of the studies so far have required relatively large amounts of leptin to elicit an effect, and it is not yet known whether such amounts are present within the hypothalamus. On the other hand, if these effects are mediated by circulating leptin, it is not clear how a large protein such as leptin can penetrate the blood-brain barrier to act within the PVN. What is certain is that the pathways controlling food intake are complex and involve many other peptides such as $\alpha$-melanocyte-stimulating hormone, neuropeptide Y, glucagon-like peptide-1, galanin and melanin-concentrating hormone, all of which may interact with $\mathrm{CRH}$ and leptin within the PVN. Reports of stimulatory and inhibitory effects of leptin on the HPA axis may reflect opposing aspects of this multicircuited interaction during obesity or malnutrition, conditions associated with dysfunctional HPA axis activity.

\section{Lipocortin-1 (LC-1)}

Lipocortins are a family of glucocorticoid-regulated antiinflammatory proteins, originally detected in immune tissues and also located within the hypothalamus and pituitary (Strijbos et al. 1991, Smith et al. 1993). It is well established that LC-1 plays a role in mediating the inhibitory effects of glucocorticoids on ACTH release (Taylor et al. 1993) but there is also evidence that LC-1 itself has intrinsic ACTHmodulating potential. It was found to inhibit interleukin (IL)-6-induced CRH release from hypothalami harvested from adrenalectomised rats, while conversely potentiating IL-6-induced AVP release (Loxley et al. 1993a). It was also found to attenuate the $\mathrm{ACTH}$ response to $\mathrm{CRH}$ in vivo and inhibit IL-1-induced depletion of $\mathrm{CRH}$ in rat hypothalami (Sudlow et al. 1996). These data are consistent with an important role for LC-1 at the hypothalamic level in mediating the HPA axis response to immune activation. Preincubation of hypothalami with LC-1 prevented CRH, but not AVP, secretion in response to a range of cytokines (Loxley et al. 1993b). This may reflect a more important role for LC-1 governing CRH rather than AVP expression during the HPA axis response to immune activation after inflammation. A 188-residue N-terminal LC-1 fragment in low picogram amounts inhibited ACTH release from rat anterior pituitary fragments (Taylor et al. 1993) in which high-affinity LC-1-binding sites are present (Christian et al. 1997), and LC-1 inhibited CRH-stimulated ACTH release from mouse pituitary AtT-20 cells (Pompeo et al. 1997). Thus LC-1, like glucocorticoids, can inhibit HPA axis activity at both the hypothalamus and pituitary. There are no data at present for the levels of LC-1 in hypophysial portal blood, but it is clear from the study by Taylor et al. (1993) that LC-1 would only need to be secreted from the ME in relatively low amounts to potently inhibit the release of ACTH.

\section{Somatostatin}

Acute restraint stress stimulates growth hormone-releasing hormone inhibitory factor somatostatin (SRIF) secretion into hypophysial portal blood (Cataldi et al. 1994), thus providing the potential for an action of SRIF at anterior pituitary corticotrophs to modulate the HPA axis response to stress. However, human studies using a long acting synthetic analogue of SRIF (sandostatin or octreotide) have largely proved negative. Sandostatin had no effect on CRH-stimulated ACTH or cortisol in normal subjects (Invitti et al. 1991), did not alter basal plasma ACTH or cortisol in patients with ACTH hypersecretion (Ambrosi et al. 1990) and had no effect upon CRH-stimulated ACTH release in patients with Cushing's disease (Stalla et al. 1994). In patients with Nelson's syndrome or ectopic ACTH syndrome characterised by very high circulating concentrations of $\mathrm{ACTH}$, peripheral administration of 
sandostatin has been used with some success in the reduction of ACTH secretion (de Herder \& Lamberts 1996), and an ACTH-secreting bronchial carcinoid tumour responded to long term treatment with sandostatin (Phlipponneau et al. 1994). SRIF inhibited the release of ACTH from human pituitary adenoma cell cultures (Stalla et al. 1994).

There is more convincing evidence for the effects of SRIF in rats: it inhibited CRH-stimulated ACTH release from isolated pituitary cells (Lamberts et al. 1989) and inhibited CRH release from hypothalami in vitro (Tizabi \& Calogero 1992). Thus SRIF is effective at both the hypothalamic and anterior pituitary levels in rodents, but the absence of evidence for an effect of SRIF in normal human subjects suggests that this peptide plays little part in regulating the human HPA axis.

\section{Prepro-thyrotrophin-releasing hormone (TRH)(178-199)}

On the basis of the original observation that ACTH release from the mouse tumour AtT-20 cell line was attenuated in cells transfected with prepro-TRH cDNA (Redei et al. 1995a), it was proposed that a peptide fragment of preproTRH could act as an inhibitor of ACTH at the anterior pituitary. In sequence deletion studies, the fragment prepro-TRH(178-199) was shown to inhibit basal and CRH-stimulated ACTH release from anterior pituitary cell cultures (Redei et al. 1995b). Intravenous injection of prepro-TRH(178-199) significantly decreased plasma $\mathrm{ACTH}$ and corticosterone responses to restraint stress whereas centrally injected prepro-TRH(178-199) was ineffective (McGivern et al. 1997). Thus prepro-TRH(178199) has emerged as a leading contender for the role of principal corticotrophin-inhibitory factor at the anterior pituitary (Redei et al. 1998). However, the data derived from these elegant studies are not supported by evidence from another group who found no effects of preproTRH(178-199) on basal or CRH-stimulated ACTH release from cultured anterior pituitary cells (Nicholson \& Orth 1996). Given the similar in vitro methodology employed by the two groups, it is difficult to evaluate the reasons for this discrepancy, and final judgement on the efficacy of prepro-TRH(178-199) as a corticotrophininhibitory factor awaits independent confirmation.

\section{Substance P (SP)}

SP, a member of the neurokinin peptide family, is found in the ME and PVN in significant amounts and has been implicated in a wide variety of neuroendocrine functions (Jessop et al. 1992). Intracerebroventricular injection of SP in rats resulted in decreased circulating ACTH (Chowdrey et al. 1990) while SP inhibited the release of CRH from rat hypothalami in vitro, but not from isolated $\mathrm{ME}$ tissue (Faria et al. 1991), indicating a role within the PVN. Injection i.c.v. of an SP antagonist peptide stimulated circulating concentrations of $\mathrm{ACTH}$ and corticosterone and increased CRH mRNA in the parvocellular subdivision of the PVN (Larsen et al. 1993), demonstrating that central endogenous SP tonically inhibits the synthesis and release of CRH. SP also exerts a tonic inhibitory influence over the HPA axis response to the chronic stress of osmotic stimulation (Larsen et al. 1993) and to the chronic inflammatory stress of adjuvant-induced arthritis (Chowdrey et al. 1995), since in both those studies parvocellular $\mathrm{CRH}$ mRNA was increased following administration of an SP antagonist. SP is involved in terminating the response to acute restraint stress, an action that is mediated centrally through the NK1 receptor (Jessop et al. 1998). This may be a direct inhibitory action on CRH expression through NK1 receptors in the parvocellular subdivision of the PVN or indirectly via a neurotransmitter-mediated pathway (Fig. 2). SP can stimulate the release of GABA (Sakuma et al. 1991) and thus may exert an inhibitory effect on $\mathrm{CRH}$ expression indirectly through GABA. Another pathway could involve serotonergic nerve terminals which abut directly on to CRH-containing cell bodies in the PVN (Liposits et al. 1987). Centrally injected SP was found to inhibit the release of serotonin in the PVN (Culman et al. 1995) and also serotonin-stimulated release of corticosterone (Saphier et al. 1994). Thus SP could endogenously inhibit stress-induced expression of CRH through inhibition of serotonin release in the PVN.

Observations that axonal terminals in the ME of the rat and primate stained strongly for SP (Hökfelt et al. 1978, Larsen 1992) raised the possibility that significant amounts of SP are released into hypophysial portal blood to act as an ACTH inhibitor directly on corticotrophs of the anterior pituitary. However, concentrations of SP are very low in hypophysial portal blood of sheep (Clarke et al. 1993), rat (Lim et al. 1990) and monkey (Eckstein et al. 1980), and SP in physiological doses had no effect on ACTH release from dispersed anterior pituitary cells in vitro (Chowdrey et al. 1990). Therefore, in the absence of evidence that SP plays any significant physiological role at the level of the anterior pituitary, it is probable that it modulates HPA axis activity by inhibiting the expression of $\mathrm{CRH}$ within the $\mathrm{PVN}$. Consequent reduction in glucocorticoid secretion is consistent with a potential pro-inflammatory role for central SP, as has been demonstrated for peripheral SP in a number of inflammatory diseases (Levine et al. 1993). Therefore, by implication, the central anti-inflammatory effects of substance $\mathrm{P}$ antagonists currently being evaluated as anti-depressants (Kramer et al. 1998) may confer an advantage compared with the pro-inflammatory effects of selective serotonin re-uptake inhibitors now widely prescribed (Harbuz et al. 1998). 


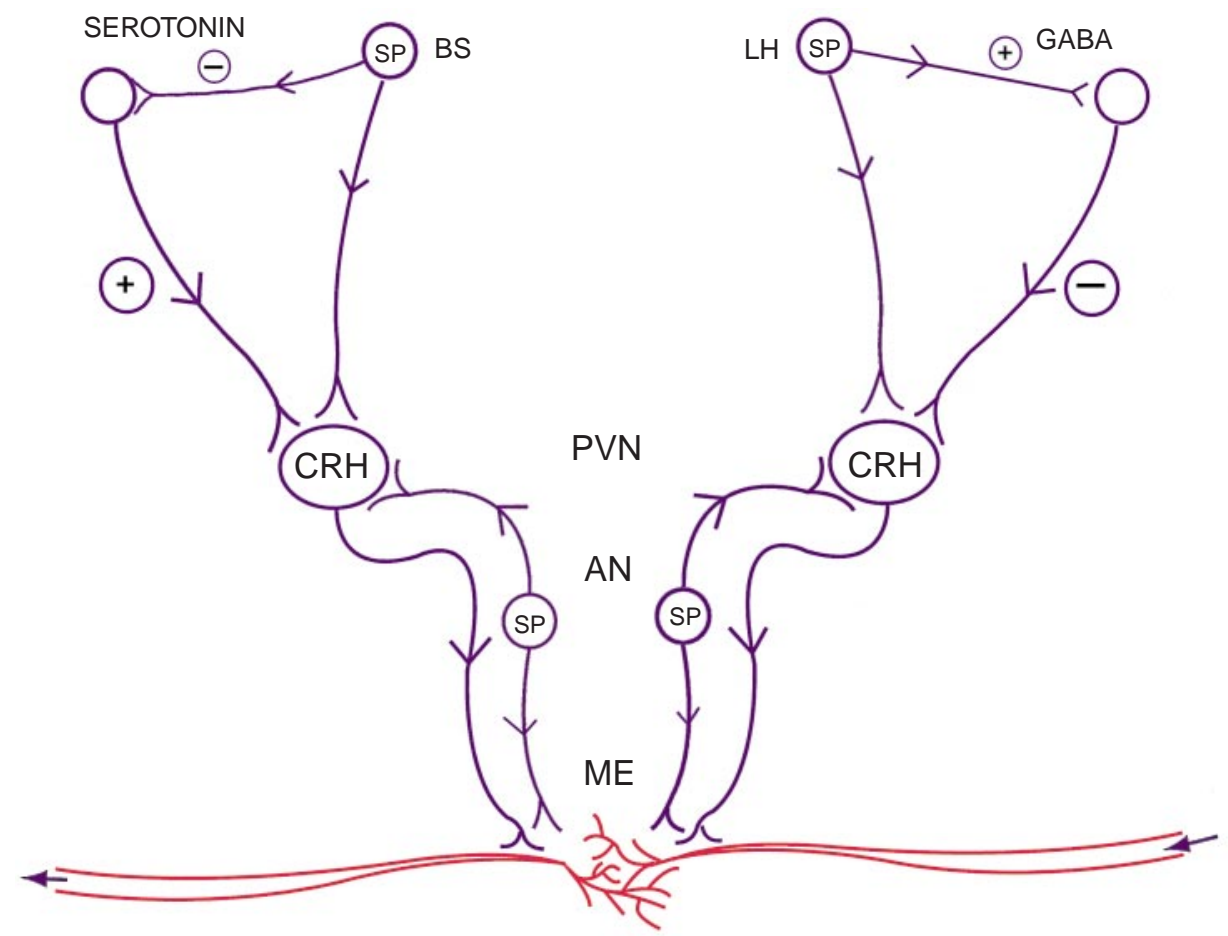

Figure 2 Possible mechanisms of SP inhibition of CRH expression in the hypothalamus. SP projections from the brain stem (BS), lateral hypothalamus ( $\mathrm{LH}$ ) and arcuate nucleus (AN) may directly inhibit axonal transport of $\mathrm{CRH}$ from cell bodies within the PVN and/or release of CRH from the ME into hypophysial portal blood. SP may also inhibit CRH expression indirectly through stimulation of GABAergic or inhibition of serotonergic inputs to $\mathrm{CRH}$-containing cells within the PVN.

\section{Oxytocin (OT)}

OT is synthesised in the magnocellular neurons of the hypothalamus and released from the posterior pituitary in response to a variety of stressors. When last reviewed by Grossman \& Tsagarakis in 1989, the literature suggested stimulatory effects of OT on ACTH release in rodents and inhibitory effects in humans. Support for the latter has been reinforced by a report that CRH-induced ACTH release was completely inhibited by an OT infusion in normal human subjects (Page et al. 1990), which suggests a direct effect on the pituitary since OT probably does not cross the blood-brain barrier in significant amounts. An inhibitory effect of OT in rats has also been reported in a model permitting rapid automated blood sampling in which the corticosterone response to a noise stress was attenuated by central infusion of OT, but not AVP (Windle et al. 1997). Although a direct pituitary effect cannot be ruled out in the latter study, the likelihood is that $\mathrm{OT}$ is acting centrally on CRH expression within the PVN, possibly in response to reduced noradrenergic tone, since noradrenaline secretion from the PVN was reduced during lactation (Toufexis et al. 1998). HPA axis activity is attenuated during lactation coincident with a period when central levels of OT are elevated (Lightman \& Young
1989). However, evidence for a stimulatory role for OT persists, with the observation that OT stimulated pulsatile release of ACTH from superfused anterior pituitary cells harvested from female rats (Link et al. 1993).

\section{Monoxide gases}

Nitric oxide (NO) and carbon monoxide (CO) have attracted considerable attention as potential modulators of the HPA axis. They are synthesised widely throughout the central nervous system, and mRNAs for their respective rate-limiting enzymes NO synthase (NOS) and haem oxygenase have been located within the PVN (Grossman et al. 1994, Vincent et al. 1994). NO is generally believed to inhibit AVP release from the hypothalamus (Yasin et al. 1993a, Grossman et al. 1997) but there has been little agreement among investigators on the influence of $\mathrm{NO}$ over CRH release. In studies on hypothalamic explants, addition of NOS substrate inhibited potassium- or IL-1induced release of CRH (Costa et al. 1993), while other investigators have reported a stimulatory effect of $\mathrm{NO}$ on CRH in vitro in response to IL-1 (Brunetti et al. 1993, Sandi \& Guaza 1995) or IL-2 (Karanth et al. 1993). In vivo data are strongly supportive of an inhibitory role for 
endogenous $\mathrm{NO}$ in mediating the HPA axis response to immune activation, since inhibition of NOS activity resulted in an enhanced release of ACTH and corticosterone in response to lipopolysaccharide or IL-1 injected i.v. (Rivier \& Shen 1994, Rivier 1995, Kim \& Rivier 1998) but not i.c.v. (Rivier \& Shen 1994, Lee \& Rivier 1998), and a NOS inhibitor further elevated inflammationinduced ACTH secretion (Turnbull \& Rivier 1996). In contrast, blocking NO synthesis attenuated the HPA axis response to footshock or water avoidance stress (Rivier 1994), suggesting that NO may be a stimulatory agent in mechanisms in the PVN that mediate acute physical or psychological stress. It has been proposed that, depending upon whether the stressor is non-immune or immune, NO may exert either a stimulatory effect on the synthesis of CRH within the PVN or an inhibitory effect upon its release from the ME (Rivier 1998). These mutually opposing influences may explain the failure of the non-immune stressors of restraint or hypertonic saline to further stimulate the HPA axis in the chronic immunological stress of adjuvant-induced arthritis (Harbuz et al. 1997).

Like those for $\mathrm{NO}$, initial reports on the actions of $\mathrm{CO}$ have been inconsistent, and two in vitro studies using rat hypothalamic tissue have shown opposite effects. Increasing substrate levels for haem oxygenase inhibited IL-1stimulated production of CRH and AVP (Pozzoli et al. 1994), an effect that was reversed by inhibition of haem oxygenase activity, while a haem analogue exerted a stimulatory effect on CRH release (Parkes et al. 1994). $\mathrm{NO}$ and $\mathrm{CO}$ selectively modulate the release of $\mathrm{CRH}$ and AVP from rat hypothalami in response to lipopolysaccharide (Kostoglou-Athanassiou et al. 1998), providing evidence for a counter-regulatory mechanism controlling the HPA axis response to immune activation. In the one in vivo study reported so far, blocking of central $\mathrm{CO}$ production decreased footshock-stimulated ACTH release (Turnbull et al. 1998), providing evidence for a stimulatory role for $\mathrm{CO}$.

Discrepancies between reports on the effects of $\mathrm{NO}$ and $\mathrm{CO}$, both in vitro and in vivo, are not really surprising since it is exceptionally difficult to obtain consistent results when dealing with compounds with biological half-lives that can be measured in seconds. Inconsistent results between laboratories may be due to different experimental methodology or sources of cytokines, doses of which are notoriously difficult to standardise. Differences between data generated in vitro and in vivo may reflect the isolated responses of tissues in vitro removed from neuronal influences. The uniform conclusion that can be derived from the literature is that the actions of $\mathrm{NO}, \mathrm{CO}$, cytokines, $\mathrm{CRH}$ and AVP are all integrated within the hypothalamus. Thus central $\mathrm{NO}$ and $\mathrm{CO}$ can act as agents in an important homoeostatic mechanism to control the HPA axis response to stimulatory effects of cytokines released peripherally during acute or chronic inflammation. This area of investigation is of great importance in elucidating the anti-inflammatory role of the HPA axis during immune activation. Differential and cooperative actions of $\mathrm{NO}$ and $\mathrm{CO}$ in paradigms of psychological or physical stress will prove a fascinating area of study, and it will be of interest to see whether the inhibitory effects of any other agents listed in this review are mediated through $\mathrm{NO}$ and/or CO.

\section{Endothelins (ETs)}

ETs are peptides with potent vasoconstrictor activity, originally isolated from endothelial tissue and also located in the brain and pituitary. ET-1, the principal mammalian form, did not affect basal release of CRH from rat hypothalamic explants (Yasin et al. 1994) and had no effect upon potassium-stimulated CRH release from rat hypothalami, but did inhibit CRH-induced ACTH release from pituitary cell cultures (Calogero et al. 1994). In contrast with these inhibitory effects, ET-1 stimulated basal ACTH secretion in rats (Calogero et al. 1994, Malendowicz et al. 1997). It has been reported that ET-1 given i.v. augmented basal and CRH-stimulated ACTH release in normal human subjects (Vierhapper et al. 1993), possibly because of increased blood pressure associated with ET-1 infusion, since both the increased ACTH and blood pressure were reversed by the calcium channel antagonist nifedipine (Vierhapper 1996). These data are difficult to interpret, since a cocktail dose of all synthetic hypothalamic releasing hormones was given to each subject, and multiple confounding interactions at the anterior pituitary cannot be discounted. Overall, there is no convincing evidence for a specific role for ET-1 in regulating the HPA axis. ET-1 stimulated the basal release of AVP from rat hypothalami in vitro (Shichiri et al. 1989, Yasin et al. 1994), but this is likely to be from magnocellular neurons which mediate the neurohypophysial response to alterations in blood pressure.

\section{Adrenomedullin (ADM)}

The potent vasodilator and hypotensive agent ADM was first reported to inhibit basal and CRH-stimulated ACTH release from pituitary cells in vitro (Samson et al. 1995). Plasma concentrations of ACTH and cortisol in the sheep were significantly reduced following i.v. ADM infusion (Parkes \& May 1995). Infusion of ADM i.c.v. actually increased circulating ACTH and cortisol in the sheep (Charles et al. 1998), although these data are difficult to interpret since cortisol levels were elevated nearly an hour before a significant increase was observed in plasma ACTH. Parkes \& May (1995) found no effects of i.c.v. infusion of ADM on plasma ACTH and cortisol. Thus ADM appears to exert a specific inhibitory action at the 
pituitary level over HPA axis activity. The N-terminal peptide fragment of pro-ADM also inhibited basal ACTH release (Samson 1998).

\section{Others}

Isolated observations have appeared of a few other compounds with HPA axis inhibitory activity. Melatonin selectively inhibited AVP, but not CRH, release from hypothalamic explants (Yasin et al. 1993b). The thymic peptide thymosin- $\alpha-1$ potently inhibited the release of hypothalamic CRH both in vivo (Milenkovic \& McCann 1992) and in vitro (Milenkovic et al. 1992), while stimulating the release of pituitary ACTH. An early report that melanin-concentrating hormone has ACTH inhibitory activity was not supported by data from Navarra et al. 1990.

\section{Concluding comments}

So why the need for such a wide range of inhibitors of HPA axis activity in addition to negative feedback from glucocorticoids? A teleological argument can be advanced that, because termination of the stress response is so important, multiple inhibitory mechanisms have evolved as a protective network should one pathway fail. There is, however, another explanation for what might seem to some to be physiological overelaboration. It is instructive to examine the complex interaction of all the components, peptides and neurotransmitters, that coordinate HPA axis responses to various stressors, and to consider whether it is likely that glucocorticoids alone, acting through only two types of receptor, can provide the complex range of controls required to terminate every type of stress, of which there is a considerable range. Although the release of CRH and AVP from the hypothalamus is considered to be the final common pathway in the stress response, it has become increasingly apparent over the last decade that different types of stress are characterised by altered contributions of CRH, AVP and probably other compounds as well, depending on whether the stress is physical, psychological, immunological, acute or chronic (Harbuz et al. 1997). These responses may in turn reflect differential stimulatory input to the hypothalamus. Thus each type of stress may have its own unique HPA axis response, defined by the timing and ratio of CRH/AVP release and contributions of other hypothalamic factors. Therefore, if selective stimulatory mechanisms are involved in mediating different types of stress at the hypothalamic level, it seems reasonable to propose that selective mechanisms of termination also exist. Discrepancies between reports on the efficacy of a particular compound may reflect the fact that certain inhibitors are of more importance in some types of stress than in others. No one compound has yet

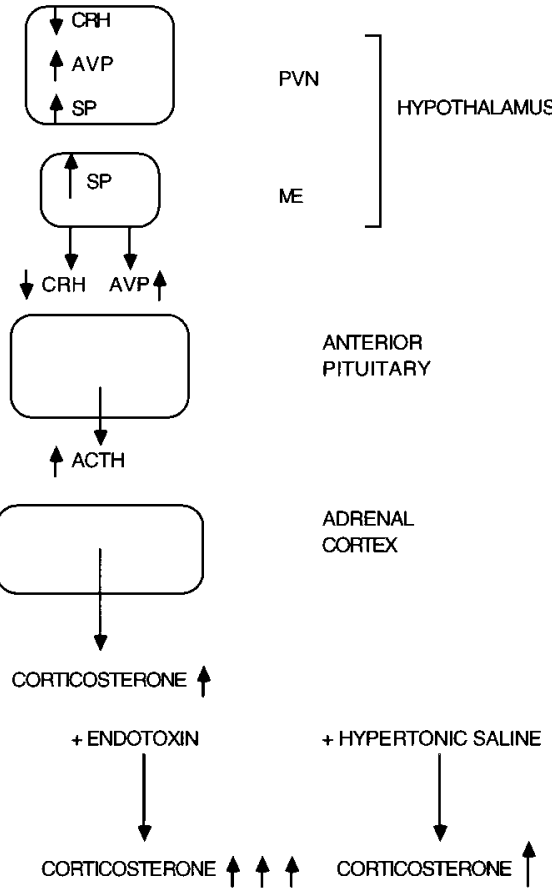

Figure 3 Putative example of stress-specific inhibition by SP. In the chronic inflammatory stress of adjuvant-induced arthritis, parvocellular CRH mRNA was decreased $(\downarrow)$ and AVP mRNA was increased $(\uparrow)$ in the presence of increased SP immunoreactivity. SP levels were elevated in the ME while CRH secretion was decreased and AVP secretion was increased. This is consistent with SP acting as a specific inhibitor of CRH, but not AVP, during this type of chronic stress. Secretion of both ACTH and corticosterone was elevated. The acute stressors of restraint or i.p. hypertonic saline failed to further stimulate corticosterone in this model whereas i.p. endotoxin strongly stimulated corticosterone secretion, suggesting that central SP may be influential in mediating acute physical or psychological, but not acute immunological, stress. Based upon data from Chowdrey et al. (1995) and Harbuz et al. (1997).

been established beyond doubt as the ACTH inhibitor and it is unlikely that one will be. Consistent with the proposal that each type of stress evokes a unique hypothalamic response, and that the site of the response is also the principal point of inhibitory control, is the cumulative evidence that most inhibitors act at the hypothalamus rather than at the pituitary (Fig. 1). Examination of the literature reveals no apparent second messenger system common to all non-glucocorticoid inhibitors whereby the actions of these agents might be integrated at the postreceptor level. Thus different mechanisms of control over CRH, AVP and ACTH expression may operate both extra- and intra-cellularly depending upon the type of stress. Likely examples of stressor-specific inhibitors are OT, which is probably responsible for attenuation of the stress response during lactation, and SP, which is associated with decreased $\mathrm{CRH}$ expression during the chronic inflammatory stress of adjuvant-induced arthritis (Fig. 3). 
In conclusion, specific mechanisms utilising stimulatory and inhibitory neuropeptides and neurotransmitters may have evolved to modulate each type of stress. The concept of stressor-specific inhibitory compounds can be tested with the availability of a new generation of antagonists to many of these compounds and by advances in oligonucleotide antisense technology allowing selective disruption of neuropeptide expression. The progress we make towards understanding the biochemical mechanisms that control stress must represent our best chance of developing therapies to counteract the deleterious effects of chronic stress that currently exact such a toll in modern society.

\section{References}

Alexander SL \& Irvine CH 1995 The effect of naloxone administration on the secretion of corticotropin-releasing hormone, arginine vasopressin, and adrenocorticotropin in unperturbed horses. Endocrinology 136 5139-5147.

Ambrosi B, Bochicchio D, Fadin C, Colombo P \& Faglia G 1990 Failure of somatostatin and octreotide to acutely affect the hypothalamo-pituitary-adrenal function in patients with corticotropin hypersecretion. Journal of Endocrinological Investigation 13 257-261.

Ambrosi B, Sala C, Bochicchio D, Colombo P, Gazzano G, Fadin C, Morganti A \& Faglia G 1994 Effect of atrial natriuretic factor infusion on basal and CRH-stimulated ACTH, cortisol and aldosterone levels in patients with Cushing's or Addison's disease. Clinical Endocrinology 40 589-594.

Antoni FA \& Dayanithi G 1989 Guanosine 3':5' cyclic monophosphate and activators of guanylate cyclase inhibit secretagogue-induced corticotropin release by rat anterior pituitary cells. Biochemical and Biophysical Research Communications $\mathbf{1 5 8}$ 824-830.

Antoni FA \& Dayanithi G 1990 Secretion of ACTH by perifused isolated rat anterior pituitary cells: pulses of secretagogue enhance the secretory response and modify the effect of atriopeptin. Journal of Endocrinology 125 365-373.

Bierwolf C, Burgemeister A, Lüthke K, Born J \& Fehm HL 1998 Influence of exogenous atrial natriuretic peptide on the pituitaryadrenal response to corticotropin-releasing hormone and vasopressin in healthy men. Journal of Endocrinology and Metabolism 83 1151-1157.

Bowman ME, Robinson PJ \& Smith R 1997 Atrial natriuretic peptide, cyclic GMP analogues and modulation of guanylyl cyclase do not alter stimulated POMC peptide release from perifused rat or sheep corticotrophs. Journal of Neuroendocrinology 9 929-936.

Boyle LL, Brownfield MS, Lent SJ, Goodman B, Vo-Hill H, Litwin J \& Carnes M 1997 Intensive venous sampling of adrenocorticotropic hormone in rats with sham or paraventricular lesions. Journal of Endocrinology 153 159-167.

Brunetti L, Preziosi P, Ragazzoni E \& Vacca M 1993 Involvement of nitric oxide in basal and interleukin-1 beta-induced CRH and ACTH release in vitro. Life Sciences 53 PL219-PL222.

Buckingham JC \& Cooper TA 1986 Effects of naloxone on hypothalamo-pituitary-adrenocortical activity in the rat. Neuroendocrinology 42 421-426.

Buckingham JC, Cowell, A-M, Gillies GE, Herbison AE \& Steel JH 1997 The neuroendocrine system: anatomy, physiology and responses to stress. In Stress, Stress Hormones and the Immune System, pp 9-47. Eds JC Buckingham, A-M Cowell \& GE Gillies. Chichester: John Wiley and Sons.

Calogero AE, Gallucci WT, Chrousos GP \& Gold PW 1988a Interaction between GABAergic neurotransmission and rat hypothalamic corticotropin releasing hormone secretion in vitro. Brain Research 463 28-36.
Calogero AE, Gallucci WT, Gold PW \& Chrousos GP 1988 b Multiple feedback regulatory loops upon rat hypothalamic corticotropin releasing hormone secretion. Journal of Clinical Investigation 82 767-774.

Calogero AE, Raiti F, Nicolosi G, Burrello N, D'Agata R \& Mantero F 1994 Effects of endothelin-1 and endothelin-3 on rat hypothalamic corticotrophin-releasing hormone and pituitary ACTH release in vitro. Journal of Endocrinology 140 419-424.

Cataldi M, Magnan E, Guillaume V, Dutour A, Sauze N, Mazzocchi L, Conte-Devolx B \& Oliver C 1994 Acute stress stimulates secretion of GHRH and somatostatin into hypophysial portal blood of sheep. Neuroscience Letters 178 103-106.

Charles CJ, Espiner EA, Richards AM \& Donald RA 1995 Central C-type natriuretic peptide augments the hormone response to hemorrhage in conscious sheep. Peptides 16 129-132.

Charles CJ, Rademaker MT, Richards AM, Cooper GJ, Coy DH \& Nicholls MG 1998 Hemodynamic, hormonal and renal effects of intracerebroventricular adrenomedullin in conscious sheep. Endocrinology 139 1746-1751.

Chowdrey HS, Jessop DS \& Lightman SL 1990 Substance P stimulates arginine vasopressin and inhibits adrenocorticotropin release in vivo in the rat. Neuroendocrinology $\mathbf{5 2} 90-93$.

Chowdrey HS, Jessop DS, Patel H \& Lightman SL 1991 Altered adrenocorticotropin, corticosterone and oxytocin responses to stress during chronic salt load. Neuroendocrinology 54 635-638.

Chowdrey HS, Larsen PJ, Harbuz MS, Lightman SL \& Jessop DS 1995 Endogenous substance P inhibits the expression of CRH during a chronic inflammatory stress. Life Sciences 57 2021-2029.

Christian HC, Taylor AD, Flower RJ, Morris JF \& Buckingham JC 1997 Characterization and localization of lipocortin 1-binding sites on rat anterior pituitary cells by fluorescence-activated cell analysis/ sorting and electron microscopy. Endocrinology 138 5341-5351.

Clarke I, Jessop D, Millar R, Morris M, Bloom S, Lightman S, Coen C, Lew R \& Smith A 1993 Many peptides that are present in the external zone of the median eminence are not secreted into the hypophysial portal blood of sheep. Neuroendocrinology 57 765-775.

Costa A, Trainer P, Besser M \& Grossman A 1993 Nitric oxide modulates the release of corticotrophin-releasing hormone from the rat hypothalamus in vitro. Brain Research 605 187-192.

Costa A, Poma A, Martignoni E, Nappi G \& Grossman A 1997 Stimulation of corticotrophin-releasing hormone release by the obese $(\mathrm{ob})$ gene product, leptin, from hypothalamic explants. Neuroreport 8 1131-1134.

Culman J, Itoi K \& Unger T 1995 Hypothalamic tachykinins: mediators of stress responses? Annals of the New York Academy of Sciences 771 204-218.

Dallman MF, Akana SF, Scribner KA, Bradbury MJ, Walker C-D, Stark AM \& Cascio CS 1992 Stress, feedback and facilitation in the hypothalamo-pituitary-adrenal axis. Journal of Neuroendocrinology 4 $517-526$

Darlington DN, Neves RB, Ha T, Chew G \& Dallman MF 1990 Fed, but not fasted, adrenalectomised rats survive the stress of hemorrhage and hypovolemia. Endocrinology 127 759-765.

De Kloet ER, Vreugdenhil E, Oitzl MS \& Joels M 1998 Brain corticosteroid receptor balance in health and disease. Endocrine Reviews 19 269-301.

Delitala G, Trainer PJ, Oliva O, Fanciulli G \& Grossman AB 1994 Opioid peptide and $\alpha$-adrenoceptor pathways in the regulation of the pituitary-adrenal axis in man. Journal of Endocrinology 141 163-168.

van Dijk G, Donahey JC, Thiele TE, Scheurink AJ, Steffens AB, Wilkinson CW, Tenenbaum R, Campfield LA, Burn P, Seeley RJ \& Woods SC 1997 Central leptin stimulates corticosterone secretion at the onset of the dark phase. Diabetes 46 1911-1914.

Eckstein N, Wehrenberg W, Louis K, Carmel P, Zimmerman E, Frantz A \& Ferin M 1980 Effects of substance P on anterior pituitary secretion in the female rhesus monkey. Neuroendocrinology 31 338-342. 
Ehrhart-Bornstein M, Hinson JP, Bornstein SR, Scherbaum WA \& Vinson GP 1998 Intraadrenal interactions in the regulation of adrenocortical steroidogenesis. Endocrine Reviews 19 101-143.

Engler D, Pham T, Fullerton MJ, Funder JW \& Clarke IJ 1988 Studies of the regulation of the hypothalamic-pituitary-adrenal axis in sheep with a hypothalamic-pituitary disconnection. Neuroendocrinology 48 551-560.

Engler D, Liu J, Clarke IJ \& Funder JW 1994 Corticotropin release inhibitory factor. Trends in Endocrinology and Metabolism 5 272-283.

Faria M, Navarra P, Tsagarakis S, Besser GM \& Grossman A 1991 Inhibition of CRF-41 release by substance $\mathrm{P}$, but not substance $\mathrm{K}$, from the rat hypothalamus in vitro. Brain Research 538 76-78.

Fink G, Dow RC, Casley D, Johnston CI, Lim AT, Copolov DL, Bennie J, Carroll S \& Dick H 1991 Atrial natriuretic peptide is a physiological inhibitor of ACTH release: evidence from immunoneutralization in vivo. Journal of Endocrinology 131 R9-R12.

Franci CR, Anselmo-Franci JA \& McCann SM 1992 The role of endogenous natriuretic peptide in resting and stress-induced release of corticotropin, prolactin, growth hormone, and thyroid-stimulating hormone. Proceedings of the National Academy of Sciences of the USA 89 11391-11395.

Grandclement B, Brisson C, Bayard F, Tremblay J, Gossard F \& Morel G 1995 Localization of mRNA coding for the three subtypes of atrial natriuretic factor (ANF) receptors in rat anterior pituitary gland cells. Journal of Neuroendocrinology 12 939-948.

Grossman A \& Besser GM 1982 Opiates control ACTH through a noradrenergic mechanism. Clinical Endocrinology 17 287-290.

Grossman A \& Tsagarakis S 1989 The hunt for the CIA: factors which demonstrate corticotrophin-inhibitory activity. Journal of Endocrinology 123 169-172.

Grossman AB, Rossmanith WG, Kabigting EB, Cadd G, Clifton D \& Steiner RA 1994 The distribution of hypothalamic nitric oxide synthase mRNA in relation to gonadotrophin-releasing hormone neurons. Journal of Endocrinology 140 R5-R8.

Grossman A, Costa A, Forsling M, Jacobs R, Kostoglou-Athanassiou I, Nappi G, Navarra P \& Satta MA 1997 Gaseous neurotransmitters in the hypothalamus. The roles of nitric oxide and carbon monoxide in neuroendocrinology. Hormones and Metabolic Research 29 477-482.

Harbuz MS, Conde GL, Marti O, Lightman SL \& Jessop DS 1997 The hypothalamic-pituitary-adrenal axis in autoimmunity. Annals of the New York Academy of Sciences 823 214-224.

Harbuz MS, Marti O, Lightman SL \& Jessop DS 1998 Alteration of central serotonin modifies onset and severity of inflammatory arthritis. British Journal of Rheumatology 37 1077-1083.

Hausler A, Monnet G \& Peter O 1993 Involvement of GABAB receptors in the regulation of the hypothalamo-pituitaryadrenocortical (HPA) axis in rats. Journal of Steroid Biochemistry and Molecular Biology 46 767-771.

Heiman ML, Ahima RS, Craft LS, Schoner B, Stephens TW \& Flier JS 1997 Leptin inhibition of the hypothalamic-pituitary-adrenal axis in response to stress. Endocrinology 138 3859-3863.

de Herder WW \& Lamberts SW 1996 Is there a role for somatostatin and its analogs in Cushing's syndrome? Metabolism 45 (Suppl 1) 83-85.

Herman JP \& Cullinan WE 1997 Neurocircuitry of stress: central control of the hypothalamic-pituitary-adrenocortical axis. Trends in Neurosciences 20 78-84.

Hökfelt T, Pernow B, Nilsson G, Wetterburg L, Goldstein M \& Jeffcoate S 1978 Dense plexus of substance P immunoreactive nerve terminals in eminentia terminalis of the primate hypothalamus. Proceedings of the National Academy of Sciences of the USA 75 1013-1015.

Huang Q, Rivest R \& Richard D 1998 Effects of leptin on corticotropin-releasing factor synthesis and CRF neuron activation in the paraventricular hypothalamic nucleus of obese $(\mathrm{ob} / \mathrm{ob})$ mice. Endocrinology 139 1524-1532.
Ibanez-Santos J, Tsagarakis S, Rees LH, Besser GM \& Grossman A 1990 Atrial natriuretic peptides inhibit the release of corticotrophinreleasing factor-41 from the rat hypothalamus in vitro. Journal of Endocrinology 126 223-228.

Inder WJ, Livesey JH, Ellis MJ, Evans MJ \& Donald RA 1996 The effect of beta-endorphin on basal and insulin-hypoglycaemia stimulated levels of hypothalamic-pituitary-adrenal axis hormones in normal human subjects. Clinical Endocrinology 44 7-13.

Invitti C, Pecori Girardi F, Dubini A, Piolini M \& Cavagnini F 1991 Effect of somatostatin on CRF-stimulated secretion of ACTH, beta-lipotropin and beta-endorphin. Hormone and Metabolic Research $23233-235$.

Jessop DS, Chowdrey HS \& Lightman SL 1990 Inhibition of rat corticotropin-releasing factor and adrenocorticotropin secretion by an osmotic stimulus. Brain Research 523 1-4.

Jessop DS, Chowdrey HS, Larsen PJ \& Lightman SL 1992 Substance P: multifunctional peptide in the hypothalamo-pituitary system? Journal of Endocrinology 132 331-337.

Jessop DS, Renshaw D, Larsen PJ, Chowdrey HS \& Harbuz MS 1998 Endogenous substance P acts centrally to terminate the HPA axis response to acute stress. Abstract P1-410, 80th Annual Meeting, Endocrine Society, New Orleans, USA.

Jezova D, Guillaume V, Jurankova E, Carayon P \& Oliver C 1994 Studies on the physiological role of ANF in ACTH regulation. Endocrine Regulation 28 163-169.

Karanth S, Lyson K \& McCann SM 1993 Role of nitric oxide in interleukin 2-induced corticotropin-releasing factor release from incubated hypothalami. Proceedings of the National Academy of Sciences of the USA $903383-3387$.

Keim SR \& Shekhar A 1996 The effects of GABA A receptor blockade in the dorsomedial hypothalamic nucleus on corticotrophin (ACTH) and corticosterone secretion in male rats. Brain Research 739 46-51

Kellner M, Herzog L, Holsboer F \& Wiedemann K 1995 Circadian changes in the sensitivity of the corticotropin-releasing hormone-stimulated HPA system after arginine vasopressin and atrial natriuretic hormone in human male controls. Psychoneuroendocrinology 20 515-524.

Kellner M, Diehl I, Knaudt K, Schule C, Jahn H \& Wiedemann K 1997 C-type natriuretic peptide exerts stimulatory effects on the corticotropin-releasing hormone-stimulated secretion of hormones in normal man. European Journal of Endocrinology 136 388-393.

Kim KC \& Rivier C 1998 Influence of nitric oxide synthase inhibitors on the ACTH and cytokine responses to peripheral immune signals. Journal of Neuroendocrinology 10 353-362.

Kiss J, Cassell M \& Palkovits M 1984 Analysis of the ACTH/ $\beta$-End/ $\alpha-\mathrm{MSH}$-immunoreactive afferent input to the hypothalamic paraventricular nucleus of the rat. Brain Research 324 91-99.

Kostoglou-Athanassiou I, Costa A, Navarra P, Nappi G, Forsling ML \& Grossman AB 1998 Endotoxin stimulates an endogenous pathway regulating corticotrophin-releasing hormone and vasopressin release involving the generation of nitric oxide and carbon monoxide. Journal of Neuroimmunology 86 104-109.

Kovacs KJ \& Elenkov IJ 1995 Differential dependence of ACTH secretion induced by various cytokines on the integrity of the paraventricular nucleus. Journal of Neuroendocrinology 7 15-23.

Kramer MS, Cutler N, Feighner J, Shrivastava R, Carman J, Sramek JJ, Reines SA, Guanahan L, Snavely D, Wyatt-Knowles E et al. 1998 Distinct mechanism for antidepressant activity by blockade of central substance P receptors. Science 281 1640-1645.

Lamberts SW, Zuyderwijk J, den Holder F, van Koetsveld P \& Hofland L 1989 Studies on the conditions determining the inhibitory effect of somatostatin on adrenocorticotropin, prolactin and thyrotropin release by cultured rat pituitary cells. Neuroendocrinology 50 44-50.

Larsen P 1992 Distribution of substance P-immunoreactive elements in the preoptic area and the hypothalamus of the rat. Journal of Comparative Neurology 316 287-313. 
Larsen P, Jessop D, Patel H, Lightman SL \& Chowdrey H 1993 Substance P inhibits the release of anterior pituitary adrenocorticotrophin via a central mechanism involving corticotrophin-releasing factor-containing neurons in the hypothalamic paraventricular nucleus. Journal of Neuroendocrinology 59-105.

Lee S \& Rivier C 1998 Interaction between corticotrophin-releasing factor and nitric oxide in mediating the response of the rat hypothalamus to immune and non-immune stimuli. Molecular Brain Research 57 54-62.

Levine JD, Fields HL \& Basbaum AI 1993 Peptides and the primary afferent nociceptor. Journal of Neuroscience 13 2273-2286.

Lightman SL \& Young WS III 1989 Lactation inhibits stress-mediated secretion of corticosterone and oxytocin and hypothalamic accumulation of corticotropin-releasing factor and enkephalin messenger ribonucleic acids. Endocrinology 124 2358-2364.

Lim A, Sheward W, Copolov D, Windmill D \& Fink G 1990 Atrial natriuretic factor is released into hypophysial portal blood: direct evidence that atrial natriuretic factor may be a neurohormone involved in hypothalamic pituitary control. Journal of Neuroendocrinology 2 15-18.

Lim AT, Dow, RC, Yang Z \& Fink G 1994 ANP(5-28) is the major molecular species in hypophysial portal blood of the rat. Peptides $\mathbf{1 5}$ $1557-1559$

Link H, Dayanithi G \& Gratzl M 1993 Glucocorticoids rapidly inhibit oxytocin-stimulated adrenocorticotropin release from rat anterior pituitary cells, without modifying intracellular calcium transients. Endocrinology 132 873-878.

Liposits Zs, Phelix C \& Paull W 1987 Synaptic interaction of serotonergic axons and corticotropin releasing factor (CRF) synthesising neurons in the hypothalamic paraventricular nucleus of the rat. Histochemistry 86 541-549.

Liposits Zs, Sievers L \& Paull W 1988 NPY and ACTHimmunoreactive innervation of corticotropin releasing factor (CRF)-synthesising neurons in the hypothalamus of the rat. Histochemistry 88 227-234.

Loxley HD, Cowell A-M, Flower RJ \& Buckingham JC 1993a Effects of lipocortin 1 and dexamethasone on the secretion of corticotrophin-releasing factors in the rat: in vitro and in vivo studies. Journal of Neuroendocrinology 5 51-61.

Loxley HD, Cowell A-M, Flower RJ \& Buckingham JC $1993 b$ Modulation of the hypothalamo-pituitary-adrenocortical responses to cytokines in the rat by lipocortin 1 and glucocorticoids: a role for lipocortin 1 in the feedback inhibition of CRF-41 release? Neuroendocrinology 57 801-814.

McGivern RF, Rittenhouse P, Aird F, Van de Kar LD \& Redei E 1997 Inhibition of stress-induced neuroendocrine and behavioural responses in the rat by prepro-thyrotropin-releasing hormone 178-199. Journal of Neuroscience 17 4886-4894.

Makara G \& Stark E 1974 Effect of $\gamma$-ABA and $\gamma$-ABA antagonistic drugs on ACTH release. Neuroendocrinology 16 178-190.

Malendowicz LK, Nussdorfer GG, Meneghelli V, Nowak M, Markowska A \& Majchrzak M 1997 Effects of endothelin-1 on the rat pituitary-adrenocortical axis under basal and stressful conditions. Endocrine Research 23 349-364.

Meister B, Hökfelt T, Geffard M \& Oertel W 1988 Glutamic acid decarboxylase and $\gamma$-aminobutyric acid-like immunoreactivities in corticotropin-releasing factor-containing parvocellular neurons of the hypothalamic paraventricular nucleus. Neuroendocrinology 48 $516-526$.

Milenkovic L \& McCann SM 1992 Effect of thymosin alpha 1 on pituitary hormone release. Neuroendocrinology 55 14-19.

Milenkovic L, Lyson K, Aguila MC \& McCann SM 1992 Effect of thymosin alpha 1 on hypothalamic hormone release.

Neuroendocrinology 56 674-679.

Mulligan RS, Livesey JH, Evans MJ, Ellis MJ \& Donald RA 1997 Atrial natriuretic peptide and C-type natriuretic peptide do not acutely inhibit the release of adrenocorticotropin from equine pituitary cells in vitro. Neuroendocrinology 65 64-69.
Navarra P, Tsagarakis S, Coy DH, Rees LH, Besser GM \& Grossman AB 1990 Rat melanin concentrating hormone does not modify the release of CRH-41 from rat hypothalamus or ACTH from the anterior pituitary in vitro. Journal of Endocrinology 127 R1-R4.

Nicholson WE \& Orth 1996 Prepro-thyrotropin-releasing hormone(178-199) does not inhibit corticotropin release. Endocrinology 137 2171-2174.

Ono N, de Castro JCB \& McCann SM 1985 Ultrashort-loop positive feedback of corticotropin (ACTH)-releasing factor to enhance ACTH release in stress. Proceedings of the National Academy of Sciences of the USA 82 3528-3531.

Page SR, Ang VT, Jackson R, White A, Nussey SS \& Jenkins JS 1990 The effect of oxytocin infusion on adenohypophyseal function in man. Clinical Endocrinology 32 307-313.

Parkes DG \& May CN 1995 ACTH-suppressive and vasodilator actions of adrenomedullin in conscious sheep. Journal of Neuroendocrinology 12 923-929.

Parkes D, Kasckow J \& Vale W 1994 Carbon monoxide modulates secretion of corticotropin-releasing factor (CRF) from rat hypothalamic cell cultures. Brain Research 646 315-318.

Patchev VK, Montkowski A, Rouskova D, Koranyi L, Holsboer F \& Almeida OF 1997 Neonatal treatment of rats with the neuroactive steroid tetrahydrodeoxycorticosterone (THDOC) abolishes the behavioural and neuroendocrine consequences of adverse early life events. Journal of Clinical Investigation 99 962-966.

Phlipponneau M, Nocaudie M, Epelbaum J, De Keyzer Y, Lalau JD, Marchandise X \& Bertagna X 1994 Somatostatin analogs for the localization and preoperative treatment of an adrenocorticotropinsecreting bronchial carcinoid tumor. Journal of Clinical Endocrinology and Metabolism 78 20-24.

Pompeo A, Luini A, Hirata F, Baldassare M \& Buccione R 1997 Neutrophil extracted lipocortin inhibits corticotropin secretion in the AtT-20 D16:16 clonal mouse pituitary cell line. Regulatory Peptides 72 169-177.

Pozzoli G, Mancuso C, Mirtella A, Preziosi P, Grossman AB \& Navarra P 1994 Carbon monoxide as a novel neuroendocrine modulator: inhibition of stimulated corticotropin-releasing hormone release from acute rat hypothalamic explants. Endocrinology 135 2314-2317.

Raber J, Chen S, Mucke L \& Feng L 1997 Corticotropin-releasing factor and adrenocorticotrophic hormone as potential central mediators of OB effects. Journal of Biological Chemistry 272 15057-15060.

Reddy DS \& Kulkarni SK 1996 Role of GABA-A and mitochondrial diazepam binding inhibitor receptors in the anti-stress activity of neurosteroids in mice. Psychopharmacology 128 280-292.

Redei E, Hilderbrand H \& Aird F 1995a Corticotropin release inhibiting factor is encoded within prepro-TRH. Endocrinology 136 1813-1816.

Redei E, Hilderbrand H \& Aird F 1995 b Corticotropin releaseinhibiting factor is prepro-thyrotropin-releasing hormone(178-199). Endocrinology 136 3557-3563.

Redei E, Rittenhouse PA, Revsky S, McGivern RF \& Aird, F 1998 A novel endogenous corticotropin release inhibiting factor. Annals of the New York Academy of Sciences 840 456-469.

Rees LH, Cook DM, Kendall JW, Allen CF, Kramer RM, Ratcliffe JG \& Knight RA 1971 A radioimmunoassay for rat plasma ACTH. Endocrinology 89 254-261.

Rivier C 1994 Endogenous nitric oxide participates in the activation of the hypothalamic-pituitary-adrenal axis by noxious stimulus. Endocrine Journal 2 367-373.

Rivier C 1995 Blockade of nitric oxide formation augments adrenocorticotropin released by blood-borne interleukin-1 $\beta$ : role of vasopressin, prostaglandins, and $\alpha 1$-adrenergic receptors. Endocrinology 136 3597-3603.

Rivier C 1998 Role of nitric oxide and carbon monoxide in modulating the ACTH response to immune and nonimmune signals. Neuroimmunomodulation 5 203-213. 
Rivier C \& Shen GH 1994 In the rat, endogenous nitric oxide modulates the response of the hypothalamic-pituitary-adrenal axis to interleukin-1 beta, vasopressin and oxytocin. Journal of Neuroscience 14 1985-1993.

Sakuma M, Yoshioka K, Suzuki H, Yanagisawa M, Onishi Y, Kobayashi N \& Otsuka M 1991 Substance P-evoked release of GABA from isolated spinal cord of the newborn rat. Neuroscience $\mathbf{4 5}$ 323-330.

Samson WK 1998 Proadrenomedullin-derived peptides. Frontiers in Neuroendocrinology 19 100-127.

Samson WK, Murphy T \& Schell DA 1995 A novel vasoactive peptide, adrenomedullin, inhibits pituitary adrenocorticotropin release. Endocrinology 136 2349-2352.

Sandi C \& Guaza C 1995 Evidence for a role of nitric oxide in the corticotropin-releasing factor release induced by interleukin-1 beta. European Journal of Pharmacology 274 17-23.

Saphier D, Welch J, Farrar G, Nguyen N, Aguado F, Thaller T \& Knight D 1994 Interactions between serotonin, thyrotropinreleasing hormone, and substance $\mathrm{P}$ in the CNS regulation of adrenocortical secretion. Psychoneuroendocrinology 19 779-797.

Sawchencko P, Swanson L \& Joseph S 1982 The distribution and cells of origin of ACTH (1-39)-stained varicosities in the paraventricular and supraoptic nuclei. Brain Research 232 365-374.

Schwartz MW, Seeley RJ, Campfield LA, Burn P \& Baskin DG 1996 Identification of targets of leptin action in rat hypothalamus. Journal of Clinical Investigation 98 1101-1106.

Shichiri M, Hirata Y, Kanno K, Ohta K, Emori T \& Marumo F 1989 Effect of endothelin-1 on release of arginine vasopressin from perifused rat hypothalamus. Biochemical and Biophysical Research Communications 163 1332-1337.

Smith T, Flower RJ \& Buckingham JC 1993 Lipocortins I, II and IV in the brain and the pituitary gland: selective induction by dexamethasone of lipocortin 1 in the anterior pituitary gland. Molecular Neuropharmacology 3 45-55.

Stalla GK, Brockmeier SJ, Renner U, Newton C, Buchfelder M, Stalla J \& Muller OA 1994 Octreotide exerts different effects in vivo and in vitro in Cushing's disease. European Journal of Endocrinology 130 125-131.

Strijbos PJLM, Tilders FJH, Carey R, Forder R \& Rothwell NJ 1991 Localization of immunoreactive lipocortin-1 in the brain and pituitary gland of the rat. Effects of adrenalectomy, dexamethasone and colchicine treatment. Brain Research 553 249-260.

Sudlow AW, Carey F, Forder R \& Rothwell NJ 1996 Lipocortin-1 inhibits CRH stimulation of plasma ACTH and IL-1 betastimulated hypothalamic CRH release in rats. American Journal of Physiology 270 R54-R60.

Tan TT, Yang Z, Haung W \& Lim AT 1994 ANF(1-28) is a potent suppressor of pro-opiomelanocortin (POMC) mRNA but a weak inhibitor of beta EP-li release from AtT-20 cells. Journal of Endocrinology 143 R1-R4.

Taylor A, Cowell A-M, Flower J \& Buckingham JC 1993 Lipocortin-1 mediates an early inhibitory action of glucocorticoids on the secretion of ACTH by the rat anterior pituitary gland in vitro. Neuroendocrinology $\mathbf{5 8} 430-439$.

Tizabi Y \& Calogero AE 1992 Effect of various neurotransmitters and neuropeptides on the release of corticotrophin-releasing hormone from the rat cortex in vitro. Synapse $10341-348$.

Torpy DJ, Grice JE, Hockings GI, Crosbie GV, Walters MM \& Jackson RV 1995 Effect of sodium valproate on naloxonestimulated ACTH and cortisol release in humans. Clinical and Experimental Pharmacology and Physiology 22 441-443.

Torpy DJ, Grice JE, Hockings GI, Walters MM, Crosbie GV \& Jackson RV 1997 Diurnal effects of fluoxetine and naloxone on the human hypothalamic-pituitary-adrenal axis. Clinical and Experimental Pharmacology and Physiology 24 421-423.

Toufexis DJ, Thrivkraman KV, Plotsky PM, Morilak DA, Ning Huang N \& Walker C-D 1998 Reduced noradrenergic tone to the hypothalamic paraventricular nucleus contributes to the stress hyporesponsiveness of lactation. Journal of Neuroendocrinology $\mathbf{1 0}$ 417-427.

Tsagarakis S, Navarra P, Rees LH, Besser M \& Grossman A 1989 Morphine directly modulates the release of stimulated corticotrophin-releasing factor-41 from rat hypothalamus in vitro. Endocrinology 124 2330-2335.

Tsagarakis S, Rees LH, Besser M \& Grossman A 1990 Opiate receptor subtype regulation of CRF-41 release from rat hypothalamus in vitro. Neuroendocrinology 51 599-605.

Turnbull AV \& Rivier C 1996 Corticotropin-releasing factor, vasopressin and prostaglandins mediate, and nitric oxide restrains, the hypothalamic-pituitary-adrenal response to acute local inflammation in the rat. Endocrinology 137 455-463.

Turnbull AV, Kim CK, Lee S \& Rivier C 1999 Influence of carbon monoxide, and its interaction with nitric oxide, on the ACTH response of the normal rat to a physico-emotional stress. Journal of Neuroendocrinology 10 793-802.

Ur E, Faria M, Tsagarakis S, Anderson JV, Besser GM \& Grossman A 1991 Atrial natriuretic peptide in physiological doses does not inhibit the ACTH or cortisol response to corticotrophin-releasing hormone-41 in normal human subjects. Journal of Endocrinology 131 163-167.

Vierhapper H 1996 Effect of endothelin-1 in man: impact on basal and stimulated concentrations of luteinizing hormone, folliclestimulating hormone, thyrotropin, growth hormone, corticotropin, and prolactin with and without pretreatment with nifedipine. Metabolism 45 658-661.

Vierhapper H, Hollenstein U, Roden M \& Nowotny P 1993 Effect of endothelin-1 in man: impact on basal and stimulated concentrations of luteinizing hormone, follicle-stimulating hormone, thyrotropin, growth hormone, corticotropin, and prolactin. Metabolism $\mathbf{4 2}$ 902-906.

Vincent SR, Das S \& Maines MD 1994 Brain heme oxygenase isoenzymes and nitric oxide synthase are co-localized in select neurons. Neuroscience 63 223-231.

Windle RJ, Shanks N, Lightman SL \& Ingram CD 1997 Central oxytocin administration reduces stress-induced corticosterone release and anxiety behaviour in rats. Endocrinology 138 2829-2834.

Witorsch RJ \& Brodish A 1972 Evidence for acute ACTH release by extrahypothalamic mechanisms. Endocrinology 90 1160-1167.

Wittert GA, Espiner EA, Richards AM, Donald RA, Livesey JH \& Yandle TG 1993 Atrial natriuretic factor reduces vasopressin and angiotensin II but not the ACTH response to acute hypoglycaemic stress in normal men. Clinical Endocrinology 38 183-189.

Yamauchi N, Shibasaki T, Wakabayashi I \& Demura H 1997 Brain beta-endorphin and other opioids are involved in stress-induced stimulation of the hypothalamic-pituitary-adrenal axis, the sympathetic nervous system, and the adrenal medulla in the rat. Brain Research 777 140-146.

Yasin SA, Costa A, Trainer P, Windle R, Forsling ML \& Grossman A $1993 a$ Nitric oxide modulates the release of vasopressin from rat hypothalamic explants. Endocrinology 133 1466-1469.

Yasin SA, Costa A, Besser GM, Hucks D, Grossman A \& Forsling ML $1993 b$ Melatonin and its analogs inhibit the basal and stimulated release of hypothalamic vasopressin and oxytocin in vitro. Endocrinology 132 1329-1336.

Yasin SA, Costa A, Navarra P, Pozzoli G, Kostoglou-Athanassiou I, Forsling ML \& Grossman A 1994 Endothelin stimulates the in vitro release of neurohypophyseal hormones, but not corticotrophinreleasing hormone, via ETA receptors. Neuroendocrinology $\mathbf{6 0}$ $553-558$.

Received 1 June 1998

Accepted 6 August 1998 